Winter 2009

\title{
Emerging Global Environmental Governance
}

\author{
N. Brian Winchester
}

Indiana University

Follow this and additional works at: https://www.repository.law.indiana.edu/ijgls

Part of the Environmental Law Commons, International Law Commons, and the Law and Politics

\section{Commons}

\section{Recommended Citation}

Winchester, N. Brian (2009) "Emerging Global Environmental Governance," Indiana Journal of Global Legal Studies: Vol. 16 : Iss. 1 , Article 2.

Available at: https://www.repository.law.indiana.edu/ijgls/vol16/iss1/2

This Symposium is brought to you for free and open access by the Law School Journals at Digital Repository @ Maurer Law. It has been accepted for inclusion in Indiana Journal of Global Legal Studies by an authorized editor of Digital Repository @ Maurer Law. For more information, please contact rvaughan@indiana.edu.

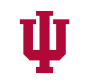

JEROME HALL LAW LIBRARY INDIANA UNIVERSITY Maurer School of Law
Blooming ton 


\title{
Emerging Global Environmental Governance
}

\author{
N. BRIAN Winchester*
}

\begin{abstract}
Environmental thinking and activism are steadily gaining widespread, even global acceptance, but are often in conflict with economic interests and international politics. Environmental priorities are further challenged by scientific uncertainty involving effects that in some cases will only become manifest far into the future. Nonetheless, accompanying this global environmental awakening has been an extraordinary number of international agreements on a wide range of critical environmental issues. While many of these environmental regimes lack adequate financial support and sanctions for non-compliance, they involve a variety of non-state actors, suggesting meaning ful movement towards an evolving, complex form of global environmental governance. Indeed, there are already examples of shared global governance where states have ceded some power to intergovernmental organizations to govern specific environmental issues, and this is almost certain to expand in the future.
\end{abstract}

\section{INTRODUCTION}

Throughout human history the impact of the environment on people has been greater than the impact of people on the environment. Communities and even entire civilizations have collapsed under the weight of environmental stress, natural and man-made. ${ }^{1}$ Only recently, however, as the population has grown exponentially, have the day-to-day decisions of billions of human beings begun affecting environmental conditions on a global scale. ${ }^{2}$

People have, of course, always been concerned with their environment. They

* Director of the Center for the Study of Global Change, Indiana University-Bloomington.

1. See generally Jared Diamond, Collapse: How Societies Choose to Fail or Succeed (2005) (examining societal collapses involving the environment, including Easter Island, the Anasazi of southwestern North America, and the Maya of Central America, among others).

2. It took all of human history until approximately 1830 for the population of Earth to reach one billion. One hundred years later it had doubled to two billion; only thirty years after that, it reached three billion. See Joel E. Cohen, How Many People Can the Earth Support? 76 (1995). According to the Population Reference Bureau, the world population reached 6.7 billion in 2008 and continues to grow by 82 million per year. Population Reference Bureau, World Population Highlights, 
are initially concerned with the obvious need to secure critical resources for survivalwater, food, shelter, and firewood. Only later do they see their own personal wellbeing as more closely linked with community-level public health, and ultimately, much later still, in symbiosis with the global environment. The very destructive nature of man-made environmental effects has been recognized for a long time. For example, urban overcrowding, absence of sewers, and increased use of coal combined to create wretched conditions in medieval Europe. The Industrial Revolution was similarly characterized by contaminated water, poisonous air, and deadly epidemics that were undoubtedly responsible for the premature death of thousands of people.

As scientific certitude began to replace superstition and ignorance, ${ }^{3}$ evidence of the relationship between sanitation, hygiene, pollution, industrialization, poverty, and disease accumulated and contributed to a public health revolution. In 1848 , a cholera epidemic killed more than sixty-two thousand people in Britain and spread to New York City, where it killed thousands more the following year. In response, the first formal international health conference was held in Paris in 1851. It was aimed at drafting international quarantine regulations, an affirmation of the international dimension of public health.

For the next half century, especially in Britain and the United States, investigative commissions were established and laws were passed to deal with various threats to public health, including water pollution, the decline of coastal fisheries, sanitation, and occupational disease. ${ }^{4}$ Significant progress was limited, however, by widespread violations, lax enforcement, ${ }^{5}$ and indifferent or even hostile courts. ${ }^{6}$

Population Bull., Sept. 2008, at 1, 1. For a growing number of scientists and environmentalists, population growth has become the most critical environmental issue of our time.

3. Influenza ("influences" in Italian), once attributed to unfavorable astrological influences, is an example of the many myths discredited by scientific discoveries, such as proof of the germ theory of disease.

4. For well-developed, online environmental timelines that focus on relevant political and economic events and legal decisions, see, for example, Environmental History Timeline, http://www .runet.edu/ wkovarik/envhist/\# (last visited Sept. 11, 2008); Environmental Movement Timeline, http://www.ecotopia.org/ehof/timeline.html (last visited Sept. 11, 2008); and National Resource Defense Council Online's Environmental Timeline, http://www.nrdc.org/features/feattime/ lineprint.html (last visited Sept. 11, 2008).

5. The U.S. Army Corps of Engineers, U.S. Bureau of Mines, and U.S. Public Health Service conducted pollution surveys beginning in 1914 and issued regular reports concluding that serious damage continued from oil dumping, mining pollution, and untreated sewage and industrial waste, even though the U.S. Congress had passed the Rivers and Harbors Act in 1889, which made it unlawful to dump garbage, oil, and other harmful chemicals into streams and navigable waterways. Environmental History Timeline, supra note 4.

6. Perhaps even more damaging was the U.S. Supreme Court decision in 1921 that allowed New Jersey to dump sewage in New York Harbor. New York v. New Jersey, 256 U.S. 296 (1921). 
As the frequency and severity of local ecosystem damage increased, and as it became clear that local events could and did produce regional and even global effects, a fundamental change in global environmental thinking and activism began to develop. With alarming regularity during the latter half of the twentieth century, there were a series of so-called "killer smogs," from London to Los Angeles, which left thousands sick and dead. A dozen major oil spills worldwide resulted in large-scale environmental degradation. ${ }^{7}$ Nuclear reactor core meltdowns occurred in the United States and the former Soviet Union, the fallout from which, in the Chernobyl case, resulted in many thousands of deaths. Far more serious, however, is the fact that our collective global actions have created a hole in the earth's fragile, protective ozone layer. ${ }^{8}$ Further, we are altering the composition of our atmosphere and impacting the hydrologic cycle, ${ }^{10}$ all with unknown and potentially catastrophic future consequences. The inescapable conclusion is that the scale of human activity has now reached the point where it negatively impacts environmental conditions globally.

\section{Environmental Summitry}

The result of the cumulative assaults on the environment was a global call to action that found concrete expression in dozens of major international environmental fora and hundreds of multilateral environmental agreements (MEAs). While

The Court said that the problem of sewage disposal was more likely to be solved by cooperative study and concessions by the states than by proceedings in any court. Id. at 313 .

7. Perhaps the best known is the grounding of the Exxon Valdez in Prince William Sound, Alaska on March 24, 1989, which spilled eleven million gallons of oil. There have, in fact, been worse spills, such as in Campeche Bay, Mexico (six hundred thousand tons of oil) and the deliberate act of enviroterrorism (in Kuwait) by retreating Iraqi armed forces in 1991 (an estimated $1,250,000$ tons of oil).

8. A link between the release of chemicals such as chlorofluorocarbons and the destruction of stratospheric ozone was first hypothesized in 1974 and confirmed a decade later. Richard Benedick, Ozone Diplomacy, Issues IN SCI. \& TECH., Fall 1989, at 43, 44. The international response (the Montreal Protocol) is discussed later in this paper.

9. Disruption of the earth's climate system is directly linked to man-made changes in the composition of greenhouse gases in our atmosphere and arguably represents the single greatest global environmental threat of the twenty-first century. This is discussed later in the paper.

10. There are forty thousand large dams worldwide, which have altered the natural course and flow of $60 \%$ of the world's major rivers. Rachel Olivieri, We're Paying the Price Today for Decades of Relentless Dam Building, ALterNet, Sept. 18, 2008, http:/www.alternet.org/water/99375/we_are_just_ beginning_to_pay_the_true_price_for_dams_/?page=entire. Such alterations have actually changed weather patterns and the hydrologic cycle. 
acknowledging the importance of early environmental conferences, Caroline Thomas of the Royal Institute for International Affairs and others regard the 1972 United Nations Conference on the Human Environment in Stockholm as a watershed event in the history of environmental concern and organization. "Symbolically important for moving what were often parochial and national environmental concerns onto the international political agenda, the Stockholm Conference was also significant in a very practical sense for setting up the United Nations Environment Programme (UNEP), which was charged with implementing the recommendations that emerged from Stockholm and from subsequent environmental conferences. ${ }^{12}$ Numerous important conferences followed, including one that created the 1987 Montreal Protocol on Substances that Deplete the Ozone Layer (Montreal Protocol) and the 1992 United Nations Conference on Environment and Development, the so-called "Earth Summit" in Rio de Janeiro, Brazil. The Rio de Janiero summit, according to Hilary French of the Worldwatch Institute, "ushered in a new era of global transnational citizen activism that is radically transforming the landscape of international diplomacy."13 The 1,500 accredited delegates to the Earth Summit from 178 states, including 114 heads of state, were outnumbered ten to one by representatives from international non-governmental organizations, businesses, farmers, and indigenous peoples organizations, all of whom were in Rio de Janiero to lobby delegates and attempt to influence conference declarations. ${ }^{14}$

After decades of international conferences at which governments found themselves increasingly maneuvered into sharing power with intergovernmental organizations, transnational corporations, and non-governmental organizations, it is appropriate to assess what has been accomplished..$^{15}$ If the metric is the more

11. See Caroline Thomas, The Environment in International Relations 24-26 (1992). Among the precursors to the Stockholm Conference are the international congresses on air pollution (1955 and 1961); the first U.N. conference on the environment (1949); the conventions on marine pollution drafted by the International Maritime Organization in the 1950s; standards to protect workers against occupational hazards adopted by the International Labor Organization in the 1920s; and transboundary agreements for protection of migratory birds and management of shared water resources prior to World War I.

12. Id. at 25.

13. Hilary French, Reshaping Global Governance, in STATE OF THE WORLD: A WORLDWATCH Institute Report on Progress Toward a Sustainable Society 2002, at 174, 189 (Linda Starke ed., 2002), available at http://www.worldwatch.org/system/files/ESW202.pdf.

14. See id. at $175,189$.

15. Hilary French no doubt speaks for many when she concludes that "many of these accords have in fact led to important results..." but "have so far mostly failed to turn around today's alarming environmental trends." Hilary French, Coping with Ecological Globalization, in STATE OF THE WORLD

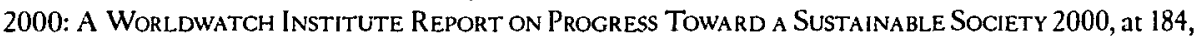


than two hundred multilateral environmental treaties and the more than one thousand bilateral agreements that have come into force to protect endangered species, restore the stratospheric ozone layer, regulate hazardous waste disposal, clean up atmospheric and oceanic pollution, and mitigate climate change, among other things, then environmental diplomacy can be judged a great success. ${ }^{16} \mathrm{On}$ the other hand, the fact is that most of these treaties lack adequate financial support, and sanctions for non-compliance are either not provided or are unenforceable. Nations continue to make only vague commitments to the treaties, which means that "even as the number of treaties climbs, the condition of the biosphere continues to deteriorate." "I In fact, glaciers are shrinking worldwide and the melting of polar ice and large areas of permafrost in Alaska, Canada, and Siberia is accelerating. Carbon dioxide levels in the atmosphere have reached record highs and climate change will continue for possibly hundreds of years, even assuming that atmospheric concentrations stabilize. Scientists are also warning that we are in the midst of a mass extinction of species, that the world's fisheries are depleted, and that water shortages loom worldwide. ${ }^{18}$

Is global environmental diplomacy, then, a case of too little, too late? The recent history regarding stratospheric ozone management demonstrates that when there is scientific consensus and public opinion is mobilized, and when the cost of compliance is relatively modest, widespread acceptance is possible. The jury is still out with regard to climate change.

\section{A. Ozone Diplomacy}

High in the earth's upper atmosphere there is a thin layer of ozone, a naturally occurring gas which protects life on earth from harmful ultraviolet (UV) radiation from the sun. The thinner the ozone layer, the more UV light reaches the earth's surface, with the result that human skin cancer, cataracts, and other health prob-

200 (Linda Starke ed., 2000), available at http://www.worldwatch.org/system/files/ESW020.pdf. Pat Mooney, an authority on agricultural biodiversity and biotechnology, is equally critical when he describes thirty years of U.N. summits as "diplomania" and "meeting monotony." Pat Mooney, Stop the Stockholm Syndrome, Dev. Dialogue, June 2006, at 203, 204-05, available at http://www.dhf.uu.se /pdffiler/DD2006_47_vol_1/DD2006_47_8.pdf.

16. Among the widely publicized successes are the Convention on International Trade in Endangered Species (CITES) and the Whaling Conventions, which have dramatically reduced both the indiscriminate killing of elephants and the annual whale "harvest," and the Montreal Protocol, which has almost completely eliminated the release of chlorofluorocarbons (CFCs) into the atmosphere.

17. French, supra note 15 , at 200.

18. Id. 
lems will increase, and agricultural production and oceanic food chains will be disrupted. Given the extent and severity of the consequences, it is not surprising that the 1974 publication of the first scientific paper hypothesizing a link between the release of chemical compounds such as chlorofluorocarbons (CFCs) and the thinning of stratospheric ozone caught the immediate attention of scientists. ${ }^{19}$ Given the dramatic increase in production of CFCs in the years leading up to 1974, it is also not surprising that the chemical industry that profited from expanding CFC production would initially deny such a link existed. ${ }^{20}$ As further scientific study confirmed the fundamental validity of the chlorine-ozone hypothesis, the popular press picked up the story, generating widespread concern.

Remarkably, even in the absence of absolute evidence and in the midst of continuing debate amongst scientists over the extent and projected rates of ozone depletion, the U.S. Congress held formal hearings in 1977. Perhaps even more remarkably, Congress decided to err on the side of caution and passed ozone protection legislation that banned the use of CFCs as aerosol propellants. U.S. producers were forced to move quickly to develop substitutes to save their multi-billion dollar industry, and U.S. production of CFCs for aerosols was rapidly reduced by 95 percent. The European Union, the other major source of CFC production, was much slower to act because it was suspicious that the United States was intending to use its competitive advantage, as a result of CFC substitution, to take market share from the European Union, a classic example of international economic competition trumping the need for international environmental cooperation. ${ }^{21}$

In 1982, the UNEP provided a non-political, international forum to begin discussions toward a global framework convention for the protection of the ozone layer. An interim agreement was reached in Vienna in 1985, but European industry representatives objected and convinced the architects of the Vienna Convention to pass a resolution to continue working on a separate CFC protocol. Negotiations continued over the next several years and were hastened by new

19. See Mario J. Molina \& F.S. Rowland, Stratospheric Sink for Chlorofluoromethanes: Chlorine Atom-catalysed Destruction of Ozone, 249 NATURE 810 (1974) (hypothesizing that chlorine reacts with stratospheric ozone to reduce ozone concentrations). Rowland and Molina were later awarded the Nobel Prize for Chemistry.

20. Richard Benedick, Depury Assistant Secretary of State for Environmental, Health, and Natural Resources, and chief U.S. negotiator for the Montreal Protocol, noted that CFC production increased from 150,000 metric tons in 1960 to more than 800,000 metric tons in 1974 as the use of CFCs as propellants in aerosol cans, insulation, refrigerants, and others, increased. He also noted that the United States and European Union accounted for $84 \%$ of CFC output worldwide. Benedick, supra note 8, at 44-45.

21. Id. at 45. 
findings by the National Aeronautic and Space Administration (NASA), UNEP, and the World Meteorological Organization that accumulations of CFCs in the atmosphere had nearly doubled between 1975 and 1985. Negotiations resumed in Montreal in late 1986 with a new sense of urgency as a result of ongoing scientific research, which indicated that ozone depletion would continue unless deep reductions were made. On September 16, 1987, the Montreal Protocol was signed by twenty-four countries, including the major CFC producers. The immediate 20 percent reduction (from 1986 levels), followed by a subsequent 30 percent reduction called for in the Montreal Protocol, were in fact quickly exceeded. ${ }^{22}$

The Montreal Protocol represents a great success in global environmental policymaking in an arena where many of the past accomplishments involved protecting endangered species but not challenging powerful global interests. What, then, accounts for the Montreal Protocol's success? First, the science with regard to ozone depletion was continually improving during the period of negotiations and strengthened the argument for a strong ozone regime. ${ }^{23}$ In addition, "[r]elevant new scientific findings now diffuse around the globe in hours or days rather than years and decades," and "contemporary environmental issues with an intercontinental dimension now move onto the agenda of public and political elites virtually simultaneously around the world."24 This greatly assisted in mobilizing public opinion. The process also benefited from the UNEP's decision to assert itself and play an increasingly important role as mediator. Finally, the United States, the largest producer of CFCs, quickly agreed to ban CFCs in aerosols, and subsequently supported a stronger regime during the negotiations in Montreal. This placed greater pressure on the European Union to follow suit. Particularly noteworthy, the Montreal Protocol represents a response to a hypothesis about a potential future environmental disaster, and it did so relatively expeditiously, at least as compared to the normal glacial pace of international diplomacy.

22. Id. at 49.

23. The "thinning" of the ozone layer over Antarctica was actually confirmed to be an "ozone hole" by American and British satellite data in 1986. In the same year, DuPont Corporation, the world's largest producer of CFCs, announced that its research had confirmed the chlorine-ozone hypothesis. Michael A. Alberty \& Stacy D. VanDeveer, International Treaties for Sustainability: Is the Montreal Protocol a Useful Model?, in Building Sustainable Societies: A Blueprint for a PostIndustrial World 93, 101 (Dennis C. Pirages ed., 1996).

24. William C. Clark, Environmental Globalization, in Governance in a Globalizing WorLD 86, 95 (Joseph S. Nye, Jr. \& John D. Donahue eds., 2000). 


\section{B. Climate Change: Scientific Certainties vs. Uncertainties}

Climate change is arguably the most urgent environmental issue on the world's agenda. The planet's climate system is directly linked to the concentration of greenhouse gases (GHGs) (carbon dioxide, methane and nitrous oxide) in the atmosphere, which allow solar radiation to pass through the atmosphere and trap heat that would otherwise bounce back into space. This "greenhouse effect" is what allows life as we know it to exist on Earth, and the strength of the greenhouse effect depends on the chemical composition of the atmosphere. If the concentration of greenhouse gases increases, the amount of heat trapped also increases. Climate science has changed from ambiguous to near-unanimous, and after rigorous debate, there is now near-universal acceptance of the significant impact that humans are having on the natural greenhouse effect. ${ }^{25}$

However, important areas of uncertainty do continue to exist. For example, carbon dioxide, the principal greenhouse gas, is constantly cycling between land, the atmosphere, and the oceans, but critical information about what determines how much carbon is sequestered in which system and the rate at which it moves between systems is lacking. Additionally, it is not known how many degrees or how fast the temperature will ultimately rise and what effect such warming will have on human health and the environment. ${ }^{26}$ Ocean and sea levels are expected to rise, climate zones and rainfall patterns to shift, and devastating weather events to intensify, but estimates of the extent of these potentially catastrophic events vary. "Conservative politicians and a few scientists, many with ties to energy companies, have variously countered that human-driven warming is inconsequential, unproved or a manufactured crisis." ${ }^{27}$ For example, U.S. Senator James Inhofe has said that global warming is the "greatest hoax ever perpetrated on the American people." ${ }^{28}$ A radically different perspective is offered by Yoweri Museveni, Presi-

25. In 2003, the American Geophysical Union and American Meteorological Society both declared that signs of global warming had become compelling. Likewise, the American Association for the Advancement of Science and the National Science Academies in the United States, Britain, China, Germany, Japan, and other nations all agreed that significant global warming is occurring. By 2006, even the Bush Administration's coordinating agency for global warming research said there was clear evidence of human influences on the climate system. See Gregg Easterbrook, Finally Feeling the Heat, N.Y. Times, May 24, 2006, at A27.

26. For a good overview of climate change science and expected impacts of global warming, see David Hunter et al., International Environmental LaW and Policy 589-653 (3d ed. 2007).

27. Andrew C. Revkin, Middle Stance Emerges In Debate Over Climate, N.Y. TimEs, Jan. 1, 2007, at A16.

28. Waking Up and Catching Up-Green America, Economist, Jan. 27, 2007, at 22. 
dent of Uganda, "whose economy depends on hydropower from a reservoir depleted by drought." ${ }^{29} \mathrm{He}$ has called climate change "an act of aggression by the rich against the poor." ${ }^{30}$ Herman Ott, who heads the Berlin office of the Wuppertal Institute for Climate, Environment, and Energy has warned that "we don't have much time. Geological and biological systems do not wait for humankind. From a certain point in time-we don't know when, but we know it is drawing nearer-the climate system will tip into a different, more dangerous state. ${ }^{.31}$ Lonnie Thompson, one of the world's foremost glaciologists, has documented glaciers and icefields receding worldwide for over thirty years.

[He] often draws an analogy between glaciers and the proverbial canary in the coal mine. Like the bird, glaciers are warning us of the buildup of dangerous gases. But there is one important difference. In the past, when the canaries stopped singing and died, the miners knew to get out of the mine. Our problem is, we live in the mine. ${ }^{32}$

Individuals, as well as countries that were once able to exploit those uncertainties as an excuse to defer action, now face a convergence of evidence from the prehistoric record, such as data from ice cores, sediments and currently observable phenomena (retreating glaciers and polar ice and data from the Earth Observing System satellites).

\section{Environmental Changes in Global Political Context}

Nonetheless, in spite of the convergence of evidence and dire predictions, and despite the fact that the vast majority of nation-states have signed the U.N. Framework Convention on Climate Change and the subsequent Kyoto Protocol, changes in the political climate have lagged behind changes in the physical climate. Sovereign states act in what they perceive as their own best interest, which often places them at odds with each other and the "global good." Less developed countries, for example, resist signing protocols that will constrain their economic growth. They demand that developed countries, responsible for most of the cumulative GHG

29. U.N. Council Hits Impasse Over Debate on Warming, N.Y. Times, Apr. 18, 2007, at A6.

30. Id.

31. Herman E. Ott, Back to San Francisco, D+C: MAG. For Dev. \& Cooperation, May 2006, at 197, 199, available at http://www.inwent.org/E+Z/content/archive-eng/05-2006/foc_art5.html.

32. J. Madeline Nash, Chronicling the Ice, SMithsonian, July 2007, at 66, 74. 
emissions, make significant reductions first. Oil-producing countries, many in the developing world, oppose policies that will result in reduced demand for oil, while countries most vulnerable to rising sea levels, many of whom are also in the developing world, such as Bangladesh and certain small island states, support strong action. Finally, the United States, until recently the largest emitter of $\mathrm{GHG},{ }^{33}$ unilaterally withdrew from the Kyoto Protocol and stands almost alone in defying the emerging global consensus. As a result, the Bush Administration has been the target of severe criticism. ${ }^{34}$ But to assume that the Administration's intransigence on climate change is tantamount to U.S. inaction is to misunderstand U.S. politics. Even if the White House has abrogated its responsibility, much of the rest of the country, at the subnational level, has not. Individual states, led by California's example, are moving to cut GHG emissions, to force automobile manufacturers to improve fuel efficiency and reduce emissions, or to promote the development of alternative energy and energyefficient buildings. ${ }^{35}$ California alone has the sixth-largest economy in the world and thus must be considered a major "player" in climate change politics. ${ }^{36}$ Similarly, over four hundred cities have signed the U.S. Mayor's Climate Protection Agreement, committing themselves to meet or exceed Kyoto Protocol targets. Their actions are more than symbolic - the combined population of these cities is equal to the population of France. ${ }^{37}$ There are currently at least a half-dozen bills pending in Congress and more than three hundred bills in forty U.S. state legislatures that address aspects of global climate change. ${ }^{38}$

\section{Pay Now or Pay More Later}

Inevitably, the stalemate over climate change policy begs comparison with the success of ozone diplomacy, especially given the many similarities. ${ }^{39}$ Both have moved from uncertainty and skepticism to broad scientific consensus. Both are serious global

33. According to a number of recent estimates, China's carbon dioxide emissions now exceed U.S. emissions. See, e.g., Maximilian Auffhammer \& Richard T. Carson, Forecasting the Path of China's CO2 Emissions Using Province-Level Information, 55 J. ENvTL. ECON. \& MGMT. 229, 229 (2008).

34. Much of that criticism has come from EU countries, most of whom, it is projected, will fall well short of Kyoto emission reduction targets themselves by the time the protocol expires in 2012.

35. See Waking Up and Catching Up - Green America, supra note 28, at 24.

36. Karen Breslau, The Green Giant, NEwsweEk, Apr. 16, 2007, at 50, 54.

37. See Anne Underwood \& Matthew Philips, Mayors Take the Lead, NEwsweEk, Apr. 16, 2007, at $68,68-70$.

38. Breslau, supra note 36 , at 56 .

39. See, e.g., Alberty \& VanDeveer, supra note 23 (comparing the similarities and differences between climate change policy and ozone diplomacy). 
threats which exceed the management capacity of individual states. Anthropogenic emissions are major contributors both to the hole in the ozone layer and to global warming. Both require action now to stave off projected environmental disaster in the future. If human institutions fail to act, the planet's natural systems will no doubt self-regulate, with unknown and potentially catastrophic consequences.

The major differences between global efforts to reverse ozone depletion and mitigate climate change are the cost of change and the number of vested interests. Phasing out CFCs involved relatively few producers and modest cost across a narrow range of commercial applications in comparison to the staggering projected cost of GHG abatement. The global economy is fossil fuel-dependent and significant reductions in GHG emissions and transitioning to alternative energy sources will be the most expensive international effort ever undertaken, but the cost of doing norhing or doing too little too late would be even greater. ${ }^{40}$ Powerful global interests are already aligning and jockeying for influence in what may prove to be the defining environmental policy confrontation of the twenty-first century.

\section{Emerging Global Environmental Governance}

While global environmentalism continues to confront apathy, ignorance, and outright hostility, evidence suggests that we are nonetheless on the threshold of a fundamental change in environmental thinking and activism on many levels. Individuals are organizing, non-governmental organizations and multinational corporations are networking, and international organizations, with authority delegated from the states, are all influencing the policy-making process in ways previously unimaginable. Evidence further suggests that as national governments are increasingly forced to share power with a proliferation of non-state actors, a highly complex system of global governance is already emerging. ${ }^{41}$ But what is global governance? James N. Rosenau has clearly framed the question.

Does it refer to a central authority that can exercise control over farflung situations on a global scale? Or is it limited to the exercise of authority in particular situations, such as environmental threats or outbreaks of widespread violence, which may be global in scope and especially dire? Or does it connote the sum of all diverse ef-

40. See id. at 96-97.

41. See James N. Rosenau, Governance in a New Global Order, in The Global Transformation ReAder 223, 225 (David Held \& Anthony McGrew eds., 2d ed. 2003). 
forts of communities at every level to move towards goals while preserving their coherence from one moment to the next? ${ }^{42}$

Rosenau, among others, concludes that global governance is not global government, but "an irreversible process [where] authority is increasingly disaggregated, resulting in a system of global governance that comprises more and more centres of authority in every corner of the world and at every level of community."33 Prominent among those proliferating centers of influence are non-state actors, such as non-governmental organizations (NGOs), multinational corporations, and certain international organizations.

\section{A. The Rise of NGOs}

One of the more significant developments in the conduct of international environmental diplomacy has been the growth of international NGOs created by and reinvigorating a broad-based citizen activism. The number of international NGOs has increased from less than two hundred in 1909 to more than twentyfour thousand in 2000, according to the Union of International Organizations, ${ }^{44}$ and it is estimated that 15 percent of those focus on environmental issues. In fact, "[n]o one knows how many NGOs there are.... One widely cited estimate claims that there are $35,000 \mathrm{NGOs}$ in developing countries... [ [I]t is impossible to measure a swiftly growing universe that includes neighborhood, professional, service, and advocacy groups, both secular and church-based, promoting every conceivable cause...." ${ }^{\prime 5}$ One measure of their growing influence is the fact that they now "deliver more official development assistance than the entire UN system (excluding the World Bank and the International Monetary Fund)." ${ }^{\prime 46}$

The role and influence of international NGOs continues to evolve from consciousness-raising and mobilizing public support, to conducting research and authoring reports, to helping shape the international environmental agenda, and even to influencing policy formulation. ${ }^{47}$ Indeed, "[t]he World Bank has acknowledged

42. Id. at 224 .

43. Id.

44. French, supra note 13, at 189.

45. Jessica T. Mathews, The Rise of Global Civil Society, in The Global Transformation Reader, supra note 41, at 204, 205.

46. Id.

47. Networks of environmental NGOs played an important role in shaping state positions and conference declarations at the 1992 Earth Summit in Rio de Janeiro and have continued to play such 
[NGOs'] critical influence in redirecting [Bank] policies." ${ }^{\text {"48 }}$ In recent years there have been a number of highly publicized actions in which NGOs played a major role, including preventing ratification of the proposed Multilateral Agreement on Investment (MAI) because of alleged environmental deficiencies, a successful campaign against clear-cutting forests in Western Canada, and opposition by European environmentalists to the importation of genetically modified food from the U.S.

Just as individuals have joined together to form NGOs, groups of NGOs, with shared values and common goals, have joined together to form transnational advocacy networks. ${ }^{49}$ While they may not be powerful in a conventional sense, by pooling resources, sharing information, and greatly increasing the size and reach of their "community of interests," their leverage and power have been enhanced. The number and diversity of such networks have grown tremendously in recent years, including such typical examples as the Climate Action Network, the Pesticide Action Network, the International NGO Network on Desertification and Drought, and the International Persistent Organic Pollutants Elimination Network. Each of these groups link hundreds of consumer, environmental, health, labor, agricultural, and public interest groups worldwide. ${ }^{50}$ "But NGOs are not the only sector to have become increasingly effective at working together across international borders: the international business community is also active at the global level."

\section{B. Transnational Corporations}

The number of transnational corporations has grown rapidly in recent decades, rising from 7,000 in 1970 to an estimated 60,000 by 2002, with annual sales in excess of $\$ 15$ trillion. ${ }^{52}$ International business has an obvious vested interest in global environmental policy, and, like other non-state actors, actively attempts to influence the policymaking process in many different areas such as climate change and pollution control. Corporations decide to pursue or not to pursue "green strategies" for a variety of reasons, including effects on profitability, consequences of non-compliance, altruism, and public relations. Some are moving from pollution

a role. See Margaret E. Keck \& Kathryn Sikkink, Environmental Advocacy Networks, in THE GLOBALization and Development Reader 370, 375 (J. Timmons Roberts \& Amy Bellone Hite eds., 2007).

48. Caroline Thomas, The Environment in International Relations 69 (1992).

49. See Hillary French, Vanishing Borders 163-76 (2000); Keck \& Sikkink, supra note 47, at $370-77$.

50. Id. at $166-67$.

51. French, supra note 13 , at 189-90.

52. Id. at 190 . 
control (cleaning up after waste is created) to pollution prevention (minimizing or eliminating waste before it is created). Ultimately, they are moving toward product stewardship (minimizing or eliminating negative environmental impact at every step in a product's life cycle, from production to distribution to disposal)..$^{53}$ But for every corporation pursuing a "green strategy," there are others hostile to what they perceive as a threat to their comparative advantage as a result of the burdens imposed by environmental regulations regarding workplace health and safety, and the manufacture, use, and dispersal of hazardous substances. An instructive example is the recent decision by U.S. automakers to take California to court to prevent more rigorous state auto emission standards from going into effect in 2015. These companies find common cause with major coal and oil corporations and other powerful economic interests in opposing climate change policies that would hurt their "bottom line." But, like NGOs, business does not speak with one voice. For example, alternative energy companies and insurance underwriters worried about climate change-related claims, among others, support strong action. Finally, there are many corporations who favor self-regulation through various business codes of conduct. Representative of the many codes to which companies currently subscribe is the Coalition for Environmentally Responsible Economies (CERES) Principle, which identifies environmental practices that companies must address such as sustainable use of natural resources; the reduction, recycling, and safe disposal of wastes; and energy efficiency, and the Business Charter for Sustainable Development (BCSD), designed to promote environmental stewardship and high standards for human health and safety. Note, however, that the BCSD, like most business codes of conduct, does not require companies to demonstrate adherence. ${ }^{54}$

\section{The Global Environment Facility: An Innovation in Global Governance}

As a consequence of the passage of so many international environmental treaties since the 1972 U.N. Conference on the Environment, each treaty created a new bureaucracy of its own to oversee implementation and to organize annual meetings of signatories. With the proliferation of agreements, what began as

53. See, e.g., Joan Magretta, Growth Through Global Sustainability, Harv. Bus. Rev., Jan.-Feb. 1997 , at 79.

54. See French, supra note 13, at 191-92; see also Tim Baines, Integration of Corporate Social Responsibility Through International Voluntary Initiatives, 16 IND. J. GLOBAL LEGAL STUD. 223, 239 (2009) (noting that lack of legal enforcement contributes to lower compliance). 
modest financial demands on ratifying states have become increasingly burdensome, especially on less-developed countries. To assist those with inadequate financial and technological resources, the Brundtland Report of the World Commission on Environment and Development ${ }^{55}$ recommended the creation of an experimental facility to help developing countries meet the terms of the treaties. Brundtland's recommendation resulted in the creation of the Global Environment Facility (GEF) on an interim basis in 1991, as a joint venture of the U.N. Development Programme (UNDP), the UNEP, and the World Bank. That collaboration, between U.N. agencies that provide technical assistance and environmental management experience; governments who provide funding on a voluntary basis; the World Bank, which is responsible for investment projects and mobilizing private sector resources; and NGOs that assist in implementing projects, has earned the GEF the reputation as an innovation in global governance. ${ }^{56}$ It is also innovative and unique among international financial institutions for its open-door policy toward NGOs and other civil society representatives and for its double-majority voting system, which is based on consecutive one-nation, onevote and one-dollar, one-vote tallies, in the event that consensus cannot be reached.

The GEF's interim status was made permanent in 1994, and it has so far provided nearly eight billion dollars in grants to developing countries and countries with economies in transition for several thousand projects addressing biodiversity, climate change, protection of international waters, and ozone depletion. In 2002 , and again in 2006, over thirty donor countries pledged three billion dollars to fund continuing operations.

The GEF, for all its apparent success, has not been immune from criticism, in particular for its alleged lack of transparency in decision-making and "the tendency of donor states to be more concerned about responding to abstract global threats than about addressing urgent local environmental needs of [recipient countries]."57 This is not surprising given the number and diversity of institutions managing and implementing GEF projects ${ }^{58}$ and the different, often conflicting interests of states and non-state actors, who are involved in GEF governance and GEF projects.

55. The World Comm'N on Envtl. and Dev., Our Common Future (1987).

56. See FrENCH, supra note 49, at 153.

57. Id. at 154 .

58. In addition to numerous NGOs, UNDP, UNEP, and the World Bank, participating agencies include the following: the Food and Agriculture Organization, the Inter-American Development Bank, the U.N. Industrial Development Organization, the Asian Development Bank, the African 


\section{Conclusion}

We are in the midst of revolutionary change on a global scale. Powerful trends, such as the globalization of economic markets, the strain on global environmental sustainability, the proliferation of networked organizations, and the global impact of new information technologies, are converging and are accelerating the pace of change to the point where it threatens to overwhelm the management capacity of individual states. State control over the cross-border flows of information, financial transactions, pollution, and criminal networks, to name just a few factors, is diminishing. Non-state actors have filled the political vacuum, and in the process, state power to manage the effects of cross-border flows has been further eroded. However, sharing power does not render states obsolete or impotent. Notwithstanding enhanced influence, non-state actors must still appeal to states to act, or seek states' approval or at least acquiescence. Of course, there is considerable variation in different states' abilities to regulate cross-border flows and negotiate with transnational organizations. Powerful states have high regulatory capacity and considerable influences among non-state actors, while poorer, less powerful states do not. ${ }^{59}$

We seem headed toward a new and as yet undefined global order, characterized in part by porous borders and power-sharing among states, non-state actors, and new geographic and/or functional entities. Indeed, Robert Keohane and Joseph Nye point out that there are already examples of shared global governance where states

cede some power to intergovernmental organizations to govern specified issues. Such delegation to broadly defined institutions takes place for trade policy (in the World Trade Organization) and fnancial and developmental policy (notably, the International Monetary Fund [IMF] and the World Bank). More limited delegation is evident in environmental policy, for example, to institutions governing chemicals depleting the ozone layer or to fisheries outside the territorial zones of states. ${ }^{60}$

Development Bank, the European Bank for Reconstruction and Development, and the International Fund for Agricultural Development.

59. See Robert J. Holton, Globalization and the Nation-State 82 (1998).

60. Robert O. Keohane \& Joseph S. Nye Jr., Introduction, in Governance in a Globalizing WORLD, supra note 24 , at $1,20$. 
While environmental values have steadily gained widespread, even global, acceptance, they are often in conflict with economic interests and international politics. Environmentalism is further challenged by scientific uncertainty involving effects that will in some cases only become manifest far into the future. Nonetheless, accompanying this global environmental awakening has been an extraordinary number of international environmental agreements. It is these international regimes, involving a variety of non-state actors, which suggest movement toward an evolving, complex form of global environmental governance. "One idea now gaining political currency is to upgrade the U.N. Environment Programme into a World Environment Organization (WEO) on a par with the WTO,"61 but what is clear is that this is no longer a matter simply for states or intergovernmental organizations. Private firms, NGOs, subunits of governments, and the transitional and transgovernmental networks that result all play a role. ${ }^{62}$ Whatever the eventual global political dispensation, there is likely to be wider participation and more transparency and accountability, and that should please democrats everywhere. To forge a more coherent global environmental management policy, governments must be persuaded that their national self-interest is inextricably tied to the global common good and to act accordingly.

61. French, supra note 15 , at 201.

62. Keohane \& Nye, supra note 60 , at 37. 


\section{Indiana University Press/Journals}

\section{Africa Today}

In the forefront in publishing Africanist, reform-minded research

PUBLISHED SEMIANNUALLY EISSN 1527-1978 pISSN 0001-9887

800-842-6796/812-855-8817 http://inscribe.iupress.org Available in electronic, combined electronic \& print, and print formats

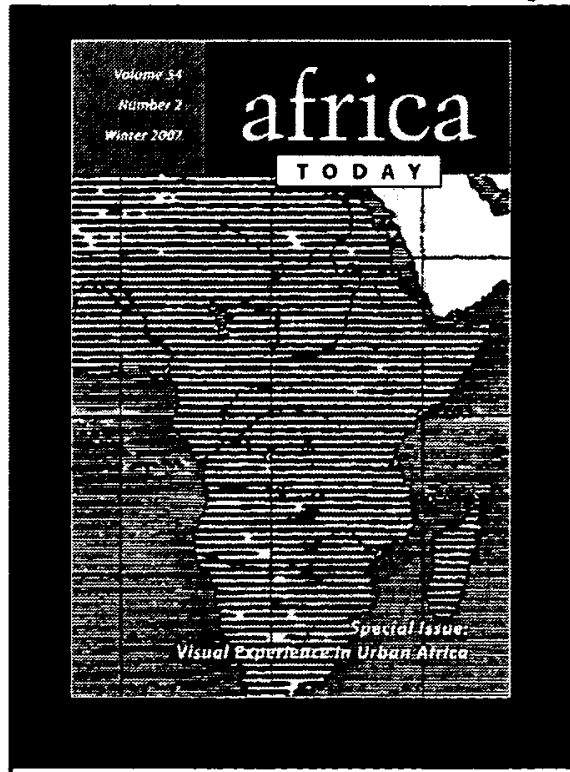

EDITED BY MARIA GROSZ-NGATÉ, EILEEN JULIEN, AND SAMUEL OBENG

Since 1954, Africa Today has been at the forefront in publishing Africanist, reform-minded research and provides access to the best scholarly work from around the world on a full range of political, economic, and social issues. Multicultural in perspective, it offers a much-needed alternative forum for serious analysis and discussion and provides perspectives for addressing the problems facing Africa today.

\section{IT | INDIANA UNIVERSITY PRESS}

